\section{Cattle disease set for cure}

\section{London}

BRITISH veterinarians were congratulating themselves last week that a disease of cattle first recognized in 1986 could have disappeared again by 1993 . That is the prediction of a working party under Sir Richard Southwood set up last year to study Bovine Spongiform Encephalopathy (BSE), a fatal neurological disease of cattle. But the prediction hangs on the enforcement of last year's regulations to prevent the feeding of cattle with feedstuffs derived from sheep infected with scrapie.

BSE is an exclusively British disease, now affecting 1 in 1,000 cattle each year. Reports of similar cases from the United States are said not to be conclusive. The working party says the cause of BSE is the agent responsible for scrapie, the spongiform encephalopathy of sheep. It is confident that the agent is not transmitted between cattle, either in utero or between adults.

On the risk that BSE may be transmitted to people, when it would presumably show up as a condition similar to JacobCreutzfeldt disease, the working party says that it has warned the Committee on the Safety of Medicines of the need for scrutiny of the sources of bovine medicinal products. Otherwise, the group asks that meat or milk from infected cattle should be kept out of the human food chain (already required by last year's legislation).

On the principle that bovine lymphatic tissues, followed by brain and nervous JAPANESE JOBS mers an informed choice. tissue, are likely to be first affected by the BSE agent, the working party considered, only to reject, the proposal that food for human consumption containing such material should be so labelled. But the government has accepted the working party's proposal that it should legislate to keep these materials out of baby food.

Several factors are thought to have been responsible for the emergence of BSE in Britain, including a significant increase of the sheep population in the 1980 s, a possible increase in the incidence of scrapie, the greater use of sheep heads in rendering (the process of extracting fat and protein from animal wastes) and new rendering processes, which may be less effective at inactivating the scrapie agent.

Not everybody accepts all the working party's conclusions. Dr James Hope, director of the neuropathogenesis unit at Edinburgh, jointly supported by the Agricultural and Food Research Council and the Medical Research Council, says that in utero transmission is likely, although there is as yet no proof. Hope would also label food products containing bovine lymphatic and nervous tissues so as to give consu-

But Hope welcomes the working party's advocacy of a research programme further to study the source and transmission of the disease. The government announced last week that a committee under Dr David Tyrrell will advise on research in progress and on priorities for the future.

Christine McGourty

\section{Students prefer finance and pay}

\section{Tokyo}

THE glitter and excitement of the financial markets is proving just as strong a lure to bright Japanese graduates as to their counterparts in the West. A survey*, released last week by the National Institute of Science and Technology Policy (NISTEP) shows a sudden downturn in science and engineering graduates entering manufacturing industry and a surge in those heading for Kabuto-cho, Tokyo's Wall Street.

At the same time, figures from the Ministry of Education, Culture and Science (MESC) show that engineering students are increasingly choosing salaried jobs rather than further education in the universities. As a result, graduate engineering schools are coming to be dominated by foreign students, principally from China and Taiwan, just as in the United States (see Nature 336, 102; 10 November 1988). In some electrical engineering departments, there are already more foreign doctoral students than there are Japanese.
The NISTEP analysis shows that science and engineering graduates entering manufacturing industry increased steadily over the two decades until 1987. Then came a sudden drop of 5-6 per cent, accompanied by a surge in numbers entering finance, insurance and property companies. A follow-up survey of ten representative universities charts the same phenomenon: engineering graduates entering manufacturing industry fell from 76 per cent in 1986 to 66 per cent in 1988 . while the percentage going into finance and insurance more than tripled.

NISTEP is not ready to say whether the shift marks a long-term change or a temporary oscillation. But it is enough to worry industrial companies which view Japan's technological edge as all important. Countermeasures, including more flexible working hours and better work conditions, are being planned. But pay levels, which are really what matters, cannot be increased without radical change to company seniority systems.

The influx of foreign students is both an

\section{French telescope seeks Indian mountain}

\section{New Delhi}

FrANCE has proposed moving one of its optical telescopes to India as the first step in a collaborative research programme in astronomy. The proposal was made by Professor Jean Audoze of the Institut d'Astrophysique de Paris at a recent conference in New Delhi of Indian and French astronomers.

The 10-year-old 1.5-metre Schmidt telescope is now at the Centre d'Etudes et de Recherches Geodynamiques and Astronomiques at Grasse, on the French Riviera. French astronomers have been looking for a new location for the telescope because Grasse, at an altitude of 1,200 metres, suffers from light-pollution from nearby Nice. Attention has focused on the Himalayan region.

Dr Jayant Narlikar, an astrophysicist at the Tata Institute of Fundamental Research in Bombay, says that relocating the telescope will be a boon for astronomers in India, where there is no such instrument.

As well as better viewing conditions, putative sites in India offer larger coverage of the southern sky. Surveys have indicated that Drusthal, near Nainital in Uttar Pradesh state at a height of 2,200 metres, will be acceptable. It has 250 clear nights a year compared with 100 at Grasse. It has been proposed that India and France will divide the cost of resiting the telescope, which will be used by both countries.

A second proposal is for a joint experiment between the University of Pune in India and the Meudon Observatory in France for detecting gravity waves using very-large-baseline interferometry with one antenna in France and another in India. K.S. Jayaraman

immediate stimulus and a longer-term worry. About 25,000 foreigners are now studying in Japan (expected to increase to 100.000 by 2000 ), almost three-quarters of them coming equally from China, Taiwan and Korea. One-fifth study engineering, mostly at the postgraduate level. By that stage many Japanese engineering students have gone to industrial companies where facilities are better and the pay is higher.

Engineering professors praise the ability and motivation of their foreign students but worry what will happen when they go home. Unlike the United States, where universities happily accept foreigners as permanent staff, Japanese universities remain relatively closed. Without change, engineering faculties may face a decline in their senior research staff just as Japan's high technology is meant to be conquering the 21 st century.

Alun Anderson * Preliminary Survey of Employment Trends for Science and Engineering Graduates soon available in English from NISTEP 1-11-39 Nagata-cho, Chiyoda-ku. Tokyo 100. Japan. 